\title{
Autocuidado da Pessoa com Diabetes Mellitus: Contribuição ao Cuidado Clínico de Enfermagem para a Prevenção do Pé Diabético*
}

\author{
Self-care of Persons with Diabetes Mellitus: Contribution to the Clinical Nursing \\ Care for the Prevention of Diabetic Foot
}

\begin{abstract}
Auto Cuidado de la Persona com Diabetes Mellitus: Contribucíon al Cuidado Clínico de Enfermería para la Prevención del Pie Diabético
\end{abstract}

Luciana Catunda Gomes de Menezes? , Maria Vilani Cavalcante Guedes?

O pé em risco é uma das complicações microvasculares graves e mutilantes de pessoas com diabetes, e, quando não diagnosticado precocemente, traz como consequência o pé diabético. Para evitar e postergar todas as complicações o paciente precisa aprender o autocuidado. O objetivo foi avaliar e classificar o pé diabético após intervenção educativa de enfermagem para promover o autocuidado. Este trabalho é um estudo quase-experimental, do tipo antes e depois, de uma intervenção com 40 pessoas diabéticas, realizada em 2013, em uma Unidade de Atenção Primária à Saúde (UAPS) de Fortaleza, Ceará. Realizou-se a intervenção educativa de enfermagem para prevenção de pé diabético e a classificação e avaliação do grau de risco, antes e após as orientações para o autocuidado. A intervenção educativa foi executada utilizando panfletos, modelos anatômicos de pés com e sem lesões e álbum seriado para pessoas com diabetes. Para coletar dados foram utilizados a entrevista semiestruturada e um formulário para avaliação clínica e exame físico do pé. A pesquisa recebeu aprovação do Comitê de Ética e Pesquisa da Universidade Estadual do Ceará (UECE) — processo n 201.279. A coleta dos dados seguiu as seguintes etapas: na avaliação inicial aplicou-se intervenção educativa por meio de orientações para o autocuidado e o exame físico dos pés; nas avaliações subsequentes foram reforçadas essas recomendações e na avaliação final foi feito outro exame físico dos pés e a retomada dos cuidados. Os dados foram expostos em tabelas e gráficos analisados por meio de estatísticas descritivas e inferenciais por meio do teste de McNemar, com nível de significância de $\mathbf{p} \leq 0,05$. Os dados evidenciam uma amostra predominantemente feminina - 62,5\%

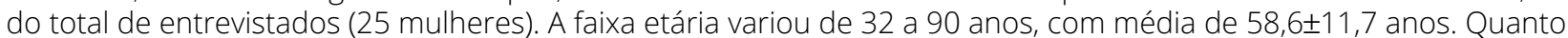
ao tempo de diagnóstico, encontrou-se uma média de $8,9 \pm 7,0$ anos. No que diz respeito às comorbidades, 28 (70,0\%) pacientes eram portadores de hipertensão arterial e 29 (72,5\%) apresentavam sobrepeso ou obesidade. Quanto aos fatores de risco, 9 (22,5\%) eram tabagistas e $14(35,0 \%)$ tinham antecedentes familiares para diabetes mellitus. Com relação aos cuidados com os pés, 25 (62,5\%) não andavam descalços, 39 (97,5\%) não usavam calçados apertados, 13 (32,5\%) hidratavam os pés, 12 (30,0\%) realizavam a lavagem dos pés e 12 (30,0\%) examinavam os pés. Quanto ao grau de risco, $17(42,5 \%)$ pacientes estavam em grau de risco 0, $10(25,0 \%)$ em grau 1, $7(17,5 \%)$ em grau 2 e $6(15,0 \%)$ em grau 3. $\mathrm{Na}$ avaliação dermatológica, realizada nos momentos inicial e final da pesquisa, foi encontrada significância estatística no corte adequado das unhas ( $p=0,0016)$, no ressecamento da pele $(p=0,0125)$, nas rachaduras $(p=0,0001)$ e nas calosidades e úlceras $(p=0,0005)$. Adotou-se a Análise de Conteúdo de Bardin para as entrevistas nas quais emergiram categorias temáticas sobre os cuidados com os pés. Destacou-se a categoria autocuidado com o pé diabético e duas subcategorias - higiene e segurança dos pés -, nas quais os pacientes descreveram os cuidados efetuados com os pés. A intervenção educativa contribuiu para o aumento do conhecimento e da aquisição de comportamento positivo para o autocuidado em pessoas com pé em risco.

DESCRITORES: Enfermagem. Diabetes mellitus. Pé diabético. Autocuidado.

\footnotetext{
*Dissertação de Mestrado apresentada ao Programa de Pós-Graduação em Cuidados Clínicos em Enfermagem e Saúde da Universidade Estadual do Ceará (UECE), em Fortaleza, em 28 de novembro de 2013.

Universidade Estadual do Ceará (UECE) - Fortaleza (CE), Brasil.

Endereço para correspondência: Luciana Catunda Gomes de Menezes - Rua Valdetário Mota, 1514, apto. 701 - Papicu - CEP: $60175-740$ - Fortaleza

(CE), Brasil - E-mail: lucianacatundagomes@yahoo.com.br

Artigo recebido em: 25/04/2016 - Aceito para publicação em: 11/10/2016
} 